\title{
Treinamento e desenvolvimento de pessoal: agregando valor às pessoas e à organização
}

\section{RESUMO}

O artigo objetiva identificar as possibilidades de inclusão de pessoas através de treinamento e desenvolvimento, realizando-se estudo no Núcleo de Capacitação Continuada dos Bombeiros Voluntários de Santa Catarina. Desenvolveu-se pesquisa participante, através de entrevista não estruturada, com perguntas abertas, em uma corporação do Vale do Itajaí que abrange três municípios, nos quais passa a rodovia BR 470, que apresenta alto índice de acidentes de trânsito. O processo seletivo para bombeiros voluntários contou com 46 inscritos, dentre eles os irmãos "P". Na primeira etapa da seleção o resultado apresentado pelos irmãos foi insatisfatório, mas por decisão do Núcleo de Capacitação Continuada ambos receberam a oportunidade de continuar considerando, não somente o desempenho, mas sua educação, simplicidade, humildade e motivação. No decorrer do treinamento observou-se a desenvoltura dos irmãos " $\mathrm{P}$ ", sendo notória a aplicação dos conhecimentos no cotidiano, com autonomia, visão de futuro e discernimento em tomar decisões. Ao término do curso os irmãos $P$ foram os únicos que apresentaram 100\% de frequência e, considerando suas dificuldades iniciais, destacaram-se no programa, sendo aprovados com mérito. Ambos optaram em tirar plantão voluntário na corporação aos domingos com escala fixa. Observa-se uma vivência singular ocorrida num treinamento para bombeiros voluntários e as várias facetas do desenvolvimento humano, considerando a decisão do querer aprender, a motivação; influência do contexto, conhecimento; o espírito de equipe e, sobretudo o valor da dignidade humana, que sobressai, sem estrelismo, mas diante dos aspectos mais singelos, como a cordialidade e o desejo de fazer o bem.

Palavras-chave: Treinamento. Desenvolvimento. Conhecimento. Motivação. Corpo de Bombeiros Voluntários.

Sérgio Luiz Bagattoli Especialista em Gestão de Pessoas Faculdade FAE Blumenau (FAE) - Brasil bagattolibnu@hotmail.com

Giane Carla Kopper Müller Mestre em Educação Faculdade de Tecnologia Senac Blumenau (SENAC) - Brasil koppermullerg@@gmail.com 


\section{INTRODUÇÃO}

O treinamento e desenvolvimento de pessoas, nos dias atuais são de suma importância para o sucesso das organizações, independente do ramo de atuação. Neste trabalho será discutida a importância do treinamento que leva ao desenvolvimento do ser humano não somente no âmbito profissional, mas também, no pessoal. O treinamento é voltado para o resultado imediato e de acordo com Chiavenato (2010) é um processo educacional de curto prazo, aplicado de maneira sistemática e organizada.

Enquanto o treinamento é orientado para o presente, o desenvolvimento é o processo executado em longo prazo e requer acompanhamento. De acordo com Chiavenato (2010), para que ocorra o desenvolvimento é necessário adquirir novas habilidades e competências, de modo que treinamento e desenvolvimento constituem processo de aprendizagem.

Para complementar esta etapa de treinar e desenvolver o ser humano temos um terceiro elemento, conforme Gil (2001), que é a educação. Esta por sua vez contribui com o aperfeiçoamento e tem a capacidade de tornar as pessoas eficazes e eficientes nas tarefas que desempenham. Para chegar a este resultado muitas organizações formam parcerias com centros educacionais e universidades visando alcançar seus objetivos.

O treinamento deve ser direcionado, sempre considerando o local e público-alvo, dando oportunidade para todos se desenvolverem, sem distinção, ou seja, não se tem o direito de negar oportunidades às pessoas, simplesmente pelo fato de "acharmos" que elas não são capazes, não tem potencial e competência para alcançar os objetivos propostos, sem ao menos haver tentado.

A parte primordial do treinamento, desenvolvimento e educação é que traz intrínseca a capacidade de promover o processo de ensino-aprendizagem produzindo o conhecimento, aliando teoria e prática, para o desenvolvimento de competências, habilidades e atitudes/valores das pessoas nas organizações.

As palavras do comandante dos Bombeiros Voluntários ao Núcleo de Capacitação Continuada (NCC) traz um exemplo fidedigno da realidade, referindo-se à oportunidade que foi dada aos irmãos que queriam participar do curso de formação 2014. "Para que fosse dada uma "chance" para eles, não pelo que eles poderiam contribuir com nossa entidade e sim pelo que nossa entidade poderia contribuir para a vida e formação deles".

\subsection{Objetivo geral}

O objetivo geral é identificar as possibilidades de inclusão de pessoas através de treinamento e desenvolvimento, realizando-se estudo no Núcleo de Capacitação Continuada dos Bombeiros Voluntários de Santa Catarina.

\subsection{Objetivos específicos}

Os objetivos específicos são:

- Verificar se o treinamento e desenvolvimento aprimoram conhecimentos;

- Avaliar a evolução dos alunos conforme as normas do curso;

- Analisar os resultados do processo.

\section{TREINAMENTO E DESENVOLVIMENTO}

Treinamento e desenvolvimento se diferenciam basicamente na perspectiva de tempo, o primeiro é a curto e o segundo em longo prazo. $O$ treinamento utilizado como um processo contínuo desenvolve as pessoas e traz outros benefícios, como pensar e compreender, o qual, proporciona conhecimento, orienta para a tomada de decisão tanto profissional quanto na vida pessoal, melhora os relacionamentos interpessoais, abre uma nova visão sobre todos os aspectos, tornando o indivíduo mais criativo e inovador. Esta discussão vai ao encontro de autores que defendem a ideia de que há diferença entre treinamento e desenvolvimento, conforme segue:

\footnotetext{
Há uma diferença entre treinamento e desenvolvimento de pessoas. Embora os seus métodos sejam similares para afetar a aprendizagem, a sua perspectiva de tempo é diferente. $O$ treinamento é orientado para o presente, focalizado no cargo atual e buscando melhorar aquelas habilidades e capacidades relacionadas com o desempenho imediato do cargo. $O$ desenvolvimento de pessoas focaliza geralmente os cargos a serem ocupados futuramente na organização e novas habilidades e competências que serão adquiridas. (CHIAVENATO, 2010, p. 367).
}

Araújo (2006, p. 92) diz"Note que treinamento e desenvolvimento (T\&D) podem enfatizar tanto a tarefa quanto a pessoa que vai executá-la, buscando um aprendizado ou aprimoramento como resultado final". Chia- 
Sérgio Luiz Bagattoli; Giane Carla Kopper Müller

venato (2010, p. 367) complementa afirmando que "Ambos, treinamento e desenvolvimento (T\&D) constituem processo de aprendizagem".

\subsection{Treinamento}

O intuito de treinar é sempre com o mesmo direcionamento: melhorar a prestação de um serviço ou um produto. De acordo com o dicionário treinamento é o "S.m. 1. ato ou efeito de treinar". (FERREIRA, 1999, p. 1995). Treinar - "tornar apto, destro, capaz, para determinada tarefa ou atividade, habilitar, adestrar, exercitar, praticar". (FERREIRA, 1999, p. 1995). Para Marras (2011, p. 133) "treinamento é o processo de assimilação cultural a curto prazo que objetiva repassar ou reciclar conhecimentos, habilidades ou atitudes relacionadas diretamente à execução de tarefas ou à sua otimização no trabalho".

Portanto, conclui-se que treinamento está intimamente relacionado com o dia a dia no cumprimento das tarefas dentro da organização, e por mais simples que seja, ele é necessário para o aprimoramento das habilidades. Para Chiavenato (2010, p. 366):

As pessoas constituem o principal patrimônio das organizações. O capital humano das organizações - composto de pessoas, que vão desde o mais simples operário ao seu principal executivo - passou a ser uma questão vital para o seu sucesso [...].

Esta afirmativa reforça que o maior bem de uma empresa são seus colaboradores, ou seja, não é o serviço ou o produto que valoriza a empresa, mas sim, quem executa o serviço ou participa do processo do produto que faz a diferença. Nesta conjuntura cabe o questionamento: A sua equipe está treinada?

É oportuno que se conheça o perfil de cada indivíduo e assim adequá-los devidamente, o que se espera do indivíduo e o que ele tem a oferecer são percepções necessárias para que o bom desempenho aconteça. As pessoas são diferentes, agem e reagem de formas adversas, de acordo com as suas crenças, cultura e educação. Porém, mesmo com essas diferenças, deverão trabalhar em grupo, desenvolvendo etapas do processo e primando pelos bons resultados.

E, de acordo com Chiavenato (2010, p. 366) "Para conseguir isso é imprescindível treinamento e desenvolvimento das pessoas", ou seja, para executar as etapas há a necessidade de treinamento e investimento, visando à melhoria do capital humano e dos resultados da organização e, vale mencionar que "A prioridade que a empresa dá ao treinamento sinaliza, para seu pessoal, a importância atribuída às pessoas" (LACOMBE, 2005, p. 313).

As empresas que não se adequarem à realidade do mercado correm sérios riscos de serem, aos poucos, esquecidas, pois, ficam aquém dos processos e por vezes tornam-se obsoletas e deixam de atender às necessidades do mercado.

É necessário que haja contínuo aperfeiçoamento do capital humano, visando manter os processos da empresa eficientes e eficazes, o que demanda mão de obra qualificada. Quanto maior for o nível do treinamento, melhor será o resultado obtido. Os treinamentos não são iguais para todos os colaboradores. Deve-se respeitar os níveis hierárquicos, avaliar as necessidades e níveis de treinamento, quando e quem vai executá-los. E, conforme Boog e Boog (2006, p. 120) "Para pessoas e empresas sobreviverem e ganharem competitividade, mais do que nunca, torna-se evidente a relevância da educação, do treinamento e do desenvolvimento contínuo".

Portanto, objetivando a contínua capacitação do potencial humano pode-se citar que a única certeza é a mudança. Sabendo disso, tanto as organizações quanto as pessoas precisam estar conscientes de que o treinamento é um processo que não tem fim, mas sim, uma continuidade. Vale lembrar que, o treinamento é de responsabilidade da organização, porém, a carreira profissional é de responsabilidade única do indivíduo.

\subsubsection{Tipos de treinamento e seus objetivos}

Conforme os objetivos são atingidos, serão classificados e relacionados de acordo com o local, podendo ser "Treinamentos internos: são os módulos de treinamentos aplicados dentro do recinto da empresa [...]. Treinamentos no Trabalho: são os módulos de treinamentos realizados ao longo de toda a permanência do empregado na empresa, [...]". (MARRAS, 2011, p. 156 - 157). Mas cabe clarificar esta questão apresentando mais detalhes, conforme segue:

Treinamentos externos: são os módulos de treinamentos aplicados fora do recinto da empresa, em geral por empresas de consultoria especializadas em treinamento ou por renomados especialistas em determinado tema especifico. Dividem-se segundo a homogeneidade do grupo, em:

Treinamento in company: sessões de treinamento realizadas somente com empregados de uma mesma empresa.

Treinamento aberto: sessões de treinamento das quais participam empregados de diversas 
empresas, formando um só grupo. (MARRAS, 2011, p. 157).

O treinamento pode ser classificado em quatro diferentes tipos quanto à forma de execução, conforme Lacombe (2005). Treinamento no trabalho, aquele que ocorre no dia a dia, treinamento formal interno, cursos e palestras de aperfeiçoamento, treinamento formal externo, aberto ao público como é o caso das universidades e a distância, a tecnologia vem auxiliando de forma positiva o treinamento à distância, palestrantes conseguem reunir filiais de empresas, grupo de pessoas em cidades diferentes, em estados diferentes e porque não dizer países, cada qual no seu local sem deslocamentos onerosos para as organizações e o palestrante pode estar em todas elas ao mesmo tempo. Conforme o objetivo a ser alcançado é que será o direcionamento do treinamento.

Quanto ao público alvo, segundo Lacombe (2005), pode ser dividido em cinco modalidades: a) Novos empregados, o qual terá informações sobre os objetivos, política da empresa, as estratégias, o produto ou serviço, normas e horários; b) Formação trainee, destinado quase sempre a quem tem curso superior, o intuito é de prepará-lo para assumir posição de responsabilidade; c) Capacitação técnico-profissional, melhorar o seu desempenho no que já faz ou capacitá-lo para outra função. d) Estágios, sem vínculo empregatício, alunos de ensino superior ou mão-de-obra técnica reconhecida oficialmente pelo governo. e) Desenvolvimento de executivos, programa que irá formar os futuros administradores de alto nível.

Importante ressaltar que o treinamento possibilita quatro tipos de mudanças no comportamento das pessoas:

- Transmissão de informação: Aumentar o conhecimento das pessoas - Informações sobre
a organização, seus produtos/serviços, políticas e diretrizes, regras e regulamentos e seus
clientes.
- Desenvolvimento de Habilidades: Melhorar as habilidades e destrezas - Habilitar para a
execução e operação de tarefas, manejo de equipamentos, máquinas, ferramentas.
- Desenvolvimentos de Atitudes: Desenvolver/modificar comportamentos - Mudança de
atitudes negativas para atitudes favoráveis, de conscientização e de sensibilidade com as
pessoas, com os clientes internos e externos.
- Desenvolvimento de conceitos: Elevar o nível de abstração - Desenvolver ideias e con-
ceitos para ajudar as pessoas a pensar em termos globais e amplos. (CHIAVENATO, 2010, p.
372, grifo nosso).

As pessoas devem estar preparadas para a execução de diversas tarefas no cargo atual e também para que possam atuar em situações mais complexas, o que demanda a necessidade de aprendizado contínuo. A questão da mudança, da atitude, serve para torná-las receptivas à novas técnicas de gestão, à mudança de rotina ou para melhorar o convívio entre seus pares.

Os treinamentos são executados com o intuito de atingir objetivos, conforme segue:

\footnotetext{
- Desenvolvimento de destrezas manipulativas necessárias para a execução de trabalhos práticos, operacionais.

- Desenvolvimento da capacidade mental do aluno, que lhe permitirá o domínio dos conhecimentos essenciais imediatos - informática, tecnologia, ciências, etc. - necessários ao bom desempenho do trabalho.

- Desenvolvimento de hábitos profissionais e atitudes necessárias ao perfeito domínio da ocupação e ao progresso do treinando.

- Desenvolvimento de certos princípios morais e cívicos, sem o que as de- mais qualidades têm seu valor reduzido.

- Desenvolvimento de capacidade de julgamento e juízo crítico que permitirão ao aluno tomar decisões quanto a determinado problema. (CARVALHO, 2001 p. 21 - 22).
}

Pela avaliação dos objetivos a serem alcançados vale mencionar Carvalho (2001) que descreve a importância do treinamento em longo prazo, pois, o seu resultado é o desenvolvimento da pessoa e os objetivos abarcam positivamente o indivíduo, pois, atingem o "Desenvolvimento de certos princípios morais e cívicos, [...]" (CARVALHO, 2001, p. 22), no indivíduo, o que está intimamente relacionado ao processo de crescimento pessoal.

Dentre os objetivos nos treinamentos, conforme Marras (2011), podemos citar os específicos e os genéricos. Sendo que os objetivos específicos abordam diretamente a formação do profissional, sua capacitação, especialização e requalificação. Os genéricos direcionam para o resultado do produto ou serviço, com o aumento da produtividade, da qualidade, otimizando o processo, estando atento para a exigência de mudança que pode atingi-la.

Durante o processo de formação, o treinamento deve ser frequente, a assimilação por parte do treinando deve ser rápida e devem ser tomados alguns cuidados como: "Clareza, precisão e originalidade na apresentação do programa de treinamento. Recursos instrucionais eficientes e adaptáveis ao treinando. Plena participação do treinando no desenvolvimento dos temas do programa de formação". (CARVALHO, 2001, p. 52 - 53). 
Sérgio Luiz Bagattoli; Giane Carla Kopper Müller

O Treinamento é vantajoso e tem a capacidade de subsidiar o desenvolvimento das pessoas, sendo também responsável pelos aspectos positivos que permeiam o processo de desenvolvimento e crescimento da organização e do colaborador.

\title{
2.2 Desenvolvimento humano
}

O desenvolvimento das pessoas é um processo em longo prazo onde é aperfeiçoada a capacidade, objetivando torná-los membros valiosos para a organização, pois é voltado para o crescimento da pessoa em nível de conhecimentos, habilidades e atitudes e o treinamento direciona para o condicionamento do colaborador na execução de tarefas. "O desenvolvimento, portanto, focaliza mais o crescimento pessoal do empregado." (DECENZO; ROBBINS, 2001, p. 137).

Para clarificar qualquer dúvida é oportuno buscar o significado de desenvolvimento no dicionário, onde lemos: "s.m. 1. Ato ou efeito de desenvolver (se); desenvolução. 2. Adiantamento, crescimento, aumento, progresso". (FERREIRA, 1999, p. 650). Para Decenzo e Robbins (2001, p. 137) "o desenvolvimento do empregado é mais orientado para o futuro e mais preocupado com a educação do que o treinamento específico para o cargo do empregado".

A cultura das organizações de investir nos seus colaboradores é recente, de modo que se procuravam candidatos com habilidades e experiências anteriores. Atualmente, há outra percepção. Investe-se nos colaboradores para que assim, eles possam se desenvolver e promover o crescimento da empresa. Porém, há de se distinguir os conceitos de se estar capacitado e de ser competente em determinada função.

\begin{abstract}
É necessário que se faça uma diferença entre capacidades e competências. Uma pessoa pode ser muito capaz, mas pouco competente em uma determinada situação. Como isso pode acontecer? É simples: imagine os melhores jogadores de futebol como Romário, Ronaldo, Ronaldinho Gaúcho e outros. Ninguém pode negar que sabem jogar futebol muito bem e que, portanto, são capazes. Mas se suas capacidades não forem transformadas em gols, de nada adianta. Para que sejam competentes, é preciso que façam gols. Desse modo, uma pessoa é capaz e se torna competente cada vez que consegue realizar algo, alcançar objetivos com a sua capacidade. (HANASHIRO; TEIXEIRA; ZACCARELLI, 2008, p. 120).
\end{abstract}

O detalhe é colocar a pessoa certa no lugar certo. Tanto para a organização quanto para o novo colaborador será uma nova experiência, uma caixa de surpresa que será aberta depois da contratação, principalmente para o colaborador que muitas vezes, o máximo que vai conseguir é referência através de outros funcionários, pela dificuldade de acesso a esse tipo de informação. Já a empresa fará um estudo sobre ele, para tentar minimizar os riscos das contratações erradas.

Para que o desenvolvimento dentro da organização ocorra, o treinamento deve atingir efetivamente os resultados que foram propostos. As pessoas se desenvolvem através do treinamento e o resultado é mais eficaz quando a proposta de realizar o treinamento está em consonância com o desejo do colaborador de meIhorar e de aprender. O indivíduo reconhece que quando evolui profissionalmente se desenvolve no âmbito pessoal.

\begin{abstract}
Treinar e desenvolver são funções de todos os envolvidos, de quem recebe o treinamento, de quem está desenvolvendo uma competência essencial ou não, ou de quem está a frente do programa como coordenador, condutor, facilitador. Esta permanente e sólida interação tem que prevalecer sempre. A inexistência dessa interação ou mesmo uma interação fraca trará um resultado fraco e, muitas vezes, o resultado fraco vai afetar os resultados globais da empresa e reduzir as chances de ganhos excepcionais. (ARAÚJO, 2006, p. 106).
\end{abstract}

As empresas devem ser incentivadoras e apoiadoras no processo de desenvolvimento de cada um de seus colaboradores, bem como, de tomar a iniciativa quando for de seu interesse, pois, se não o fizer, perderá talentos e a concorrência está aí para recrutá-los.

É notório por parte das pessoas que querem destacar-se como bons profissionais no mercado de trabalho, a iniciativa de estarem se preparando e não esperando que o mercado o faça. Isso não significa que as empresas não irão desenvolvê-las, ao contrário, quanto melhor capacitada para seu cargo, melhor será o seu desempenho dentro da organização. Mesmo sem perceber, o funcionário tira proveito da necessidade que a organização tem em treiná-los. "É importante considerar um componente crítico do desenvolvimento do empregado: todos os empregados, independentemente do nível, podem ser desenvolvidos". (DECENZO; ROBBINS, 2001, p. 137).

Essa ambiência empresarial afeta o desenvolvimento das pessoas que nela trabalham, tanto como profissionais, como pessoas em sua totalidade, aspectos que, em muito, podem superar a importância da remuneração recebida pelo trabalho prestado. No entanto, nem 
todos os indivíduos atentam para esse fato no momento de escolherem, ou analisarem uma proposta de trabalho. (HANASHIRO; TEIXEIRA; ZACCARELLI, 2008, p. 152).

O desenvolvimento das pessoas na organização é um conjunto de experiências de aprendizagem, para a melhoria do desempenho e/ou crescimento humano que é proporcionado dentro de um período de tempo de forma intencional e proposital pelas organizações.

A partir do treinamento, desenvolvimento e educação, mudam-se aspectos profissionais e pessoais. Mudam-se os comportamentos, abrem-se novos horizontes e possibilita-se crescer e propagar atitudes mais positivas. Cabe ressaltar que o desenvolvimento se diferencia do treinamento pelo fato de que o resultado do desenvolvimento é a médio e longo prazo. Para o pleno desenvolvimento de uma pessoa há a necessidade não apenas de treinamento, mas de educação.

\subsection{Comportamento organizacional}

O comportamento organizacional está intimamente relacionado com a informação, formando assim a gestão do conhecimento: "a síntese da cultura de informação e cultura organizacional é uma parte integrante do processo de se tornar uma organização baseada no conhecimento" (CURRY; MOORE, 2003, p. 95); "o conhecimento é orientado à ação" (NONAKA; TAKEUCHI, 1997, p. 63).

\subsubsection{Conhecimento}

O conhecimento está essencialmente relacionado à ação humana, que o caracteriza, todavia, Almeida (2011, p. 4) destaca "Ao contrário da informação, o conhecimento envolve crenças e compromissos e está necessariamente ligado à ação; por outro lado, à semelhança da informação, o conhecimento relaciona-se com o significado de algo". O conjunto destes fatores e a relação com o meio resulta no conhecimento, ou seja, "o conhecimento pode ser comparado a um sistema vivo, que cresce e se modifica à medida que interage com o meio ambiente". (DAVENPORT; PRUSAK, 1998, p. 6).

Para complementar, o Quadro 1 apresenta a diferença entre dados, informação e conhecimento.

Quadro 1 - Distinção entre dado, informação e conhecimento

\begin{tabular}{|l|l|l|}
\hline \multicolumn{2}{|c|}{ Dados, Informação e Conhecimento } \\
\hline \multicolumn{1}{|c|}{ Dados } & \multicolumn{1}{|c|}{ Informação } & \multicolumn{1}{c|}{ Conhecimento } \\
\hline - Simples observações sobre & $\begin{array}{l}\text { - Dados dotados de relevância e } \\
\text { propósito. }\end{array}$ & $\begin{array}{l}\text { - Informação valiosa da mente } \\
\text { Humana } \\
\text { o estado do mundo }\end{array}$ \\
$\begin{array}{l}\text { - Facilmente estruturado } \\
\text { - Facilmente obtido por máquinas } \\
\text { - Frequentemente quantificado } \\
\text { - Facilmente transferível }\end{array}$ & $\begin{array}{l}\text { - Exige consenso em relação ao } \\
\text { significado } \\
\text { - Exige necessariamente a } \\
\text { mediação humana }\end{array}$ & $\begin{array}{l}\text { - Inclui reflexão, síntese, contexto } \\
\text { - De difícil estruturação captura em máquinas }\end{array}$ \\
\hline
\end{tabular}

Fonte: Davenport e Prusak (1998, p. 18).

Para chegar ao conhecimento são necessários dados, informações e a integração com o meio gerando inovação e competitividade, pois, "a informação tem por finalidade mudar o modo como o destinatário vê algo, exercer algum impacto sobre seu julgamento e comportamento" (DAVENPORT; PRUSAK, 1998, p. 5). A distribuição deste conhecimento é entendida como "a atividade de disponibilizar os conhecimentos que já se encontram na organização, tornando-os disponíveis a todos os colaboradores que poderão precisar deles" (ALMEIDA, 2011, p. 84). Algumas pessoas, por medo de perderem seus cargos, limitam informações, consequentemente o potencial de uma organização.

\subsubsection{Motivação}

O que motiva uma pessoa a fazer algo que acreditava não conseguir fazer? Segue um exemplo ouvido em um treinamento quando feita a seguinte pergunta: O que motivou você a fazer o curso de Atendimento Pré-Hospitalar (APH)?

A resposta, "Minha mãe teve um problema cardíaco e eu não sabia o que fazer, fiquei tão apavorada que não consegui nem chamar o serviço de emergência. Ela morreu nos meus braços, não quero mais passar por 
Sérgio Luiz Bagattoli; Giane Carla Kopper Müller

isso, sentir-me impotente para ajudar alguém nesse sentido, e foi isso o que me motivou" (Cursista APH).

Segundo Ferreira (1999), essa afirmativa diz respeito ao conjunto “[...] de fatores psicológicos (conscientes ou inconscientes) de ordem fisiológica, intelectual ou afetiva, os quais agem entre si e determinam a conduta de um indivíduo", podendo ser entendido como motivação, a qual é definida por Chiavenato (1994, p. 165) "[...] a motivação pode ser conceituada como o esforço e tenacidade exercidos pela pessoa para fazer algo ou alcançar algo". E vai além, afirmando que a motivação é impulsionada pelo desejo e pelo receio: I. desejo - as pessoas desejam status/reconhecimento, aceitação, poder; II. receio - as pessoas receiam ameaças, abandono/ exclusão social, discriminação.

A motivação é a pressão interna surgida de uma necessidade, também interna, que excitando (via eletroquímica) as estruturas nervosas, origina um estado energizador que impulsiona o organismo à atividade iniciando, guiando e mantendo a conduta até que alguma meta (objetivo, incentivo) seja conseguida ou a resposta seja bloqueada [...]. (SOTO, 2002, p. 118).

Sob essa concepção, Morgan (1996, p. 56) destaca que:

É o processo de motivação que governa escolhas entre comportamentos; é uma espécie de força interna que emerge, regula e sustenta todas as nossas ações mais importantes. Geralmente é empregado como sinônimo de forças psicológicas, desejos, impulsos, necessidades, vontade, intenção e etc.

A motivação, seja ela consciente ou inconsciente, interna ou externa, está presente no dia a dia quer seja para um resultado que pode afetar uma comunidade inteira ou apenas, você. A motivação estimula e faz acontecer. Porém, ela é individual, o que motiva uma pessoa pode não motivar a outra.

\section{PROCEDIMENTOS METODOLÓGICOS}

Para desenvolver este trabalho realizamos pesquisas bibliográficas para embasar nossas discussões e aprofundar conhecimento referente à temática, pois, "[...] toda e qualquer classificação se faz mediante algum critério. Com relação às pesquisas, é usual a classificação com base em seus objetivos gerais. " (GIL, 2002, p. 41).

A forma participante que ocorre por meio do contato direto do pesquisador com o fenômeno observado para se obter informações sobre a realidade dos atores sociais em seus próprios contextos. Quando se comenta em participação, ela é muito abrangente e não se limita a apenas um fator, mas, devem-se considerar as causas e efeitos.

A coleta de dados deste trabalho foi realizada no decorrer do treinamento de pessoas participantes do curso de formação de bombeiros cuja coleta se dará no decorrer de todo o processo, ou seja, "A coleta de dados significa a fase da pesquisa em que se indaga e se obtém dados da realidade pela aplicação de técnicas. " (BARROS; LEHFELD, 2000, p. 89).

Foi utilizada a entrevista não estruturada que se caracteriza por ser totalmente aberta, pautando-se pela flexibilidade e pela busca do significado, na concepção do entrevistado, ou seja, "permite ao entrevistado responder perguntas dentro da sua própria estrutura de referências" (MAY, 2004, p. 149). A conversação é efetuada verbalmente e as informações necessárias serão apresentadas de maneira metódica e face a face. $\mathrm{O}$ entrevistador tem liberdade para desenvolver cada situação em qualquer direção. Permite explorar mais amplamente uma questão.

O feedback é uma orientação, a qual pode ser considerada por quem a recebe ou executa. Refere-se à troca de opiniões, sugestões e críticas sobre o desempenho, comportamento, podendo ser individual ou em grupo dependendo do ponto a ser atingido. Se ficarmos diante de um espelho, ele pode contribuir para a meIhoria de alguns pontos, a finalidade do feedback é exatamente esta.

Há muitas teorias sobre tipos "ideais" de feedback, como este trabalho trata de treinamento e desenvolvimento, ou seja, envolve diretamente a relação professor/aluno, vamos nos ater a definição de Willians (2005), que apresenta os seguintes tipos de feedback:

a) Positivo: tem a função de reforçar um comportamento que desejamos que se repita. Deve ser utilizado sempre, mesmo que as pessoas já estejam agindo conforme desejamos. Isto evitará que elas deixem de agir adequadamente por falta de motivação.

b) Corretivo: tem por objetivo modificar um comportamento. Quando uma pessoa não está agindo adequadamente deve-se emitir um feedback deste tipo, tomando os devidos cuidados para não dar um feedback ofensivo. Fazer esta diferenciação é um grande desafio para o professor.

c) Insignificante: é um feedback vago ou genérico a ponto de confundir o aluno sobre o seu propósito. Não provoca a reação desejada no aluno, como por exemplo, que ele continue estudando e interessando-se pela disciplina. 
d) Ofensivo: Este tipo de feedback que não orienta, não permite a aprendizagem pelo erro e não motiva para os estudos. Pelo contrário, acaba por gerar conflitos entre o professor e o aluno que o recebe. (WILLIANS, 2005, p. 52).

As pessoas esperam o retorno, se não o recebem ocorre um sentimento de vazio. Isso ocorre quando está sendo desenvolvido determinado trabalho e não há comentários sobre o que está acontecendo, subentende-se que está tudo bem, pois, não há troca de informações e acredita-se estar acertando. Neste contexto pode-se dizer que o feedback é um presente, porque nos possibilita crescer como seres humanos e como profissionais.

\subsection{Critérios para Análise dos Dados}

Definiu-se como método qualitativo, pois, leva em consideração que entre o sujeito e o mundo real há uma relação dinâmica que não pode ser traduzida em números. Une-se o mundo objetivo e a subjetividade do sujeito criando um vínculo indissociável. Leva em consideração o "mundo lá fora" e não em laboratório.

Portanto, "as múltiplas e fragmentadas histórias da pesquisa qualitativa possibilitam que qualquer pesquisador vincule um projeto a um texto canônico de qualquer um dos momentos descritos" (DENZIN; LINCOLN, 2006, p. 32). Porém, “Em certo sentido, todos os métodos de pesquisa são, no fundo, qualitativos. O emprego de dados quantitativos ou procedimentos matemáticos não elimina o elemento intersubjetivo que representa a base da pesquisa social" (VIDICH; LYMAN, 2006, p. 49). Neste caso, não requer técnicas e métodos estatísticos, sendo o pesquisador o instrumento chave e o ambiente natural, a fonte direta para coleta de dados.

\subsection{Descrição das Etapas de Investigação}

Muitas pessoas têm um pensamento errôneo sobre o Bombeiro Voluntário. Acreditam que uma pessoa que voluntaria, apresenta-se no Corpo de Bombeiro e executa este serviço, mas, não é tão simples. Para se formar um Bombeiro Voluntário não basta apenas querer, tem que querer muito, passar por um processo de seleção simples, porém, a seleção natural é muito mais acirrada. O que é seleção natural?

Vamos esclarecer: Durante 9 meses de curso (março a novembro) os alunos comparecem aos sábados, das $14 \mathrm{~h}$ até $18 \mathrm{~h}: 30$ e um domingo por mês das $8 \mathrm{~h}$ às $18 \mathrm{~h}$, em treinamento, podendo ter no máximo 3 faltas justificadas nesse período, sendo o acampamento obrigatório. Em relação às avaliações, exige-se que o aluno obtenha média 7 no desempenho teórico, e na prática ele será avaliado como apto ou não. Não há meio termo. Isso demonstra a seleção natural que irão enfrentar.

Por que tudo isso? Mesmo sendo um serviço voluntário é um compromisso assumido com a comunidade e terá que lidar com vidas humanas. O curso de formação tem a duração de um ano, acrescido de mais um ano de estágio supervisionado. A turma formada em 2014, realizará o estágio supervisionado em 2015, com certificação para 2016, quando cumprida as etapas, e será considerada apta ao exercício de bombeiro.

Para desenvolver a pesquisa foram escolhidos os sujeitos e a instituição, cujos nomes serão preservados, de modo que os respectivos nomes serão representados pelo Alfabeto Fonético Internacional, ou seja, pela primeira letra de cada nome. A instituição como sendo Bombeiros Voluntários dos municípios Alpha-Bravo-Charlie (A-B-C).

Municípios foram identificados Alpha (A), Bravo (B), Charlie (C), Índia (I), Tango (T). O pesquisador e instrutor foi denominado como Sierra Lima Bravo (S.L.B), já o Comandante dos Bombeiros Voluntários da cidade (I) como Echo Victor (E.V.) o Comandante da instituição como Juliet Juliet Mike (J.J.M.), o Subcomandante como Echo Sierra (E.S.), o Instrutor participante como Echo Whiskey Mike (E.W.M.), os alunos como Sierra Mike Papa (S.M.P.) e Mike Papa (M.P.), ou como irmãos Papa (P.), um amigo como Charlie Bravo (C.B.) e outro colega como Foxtrot Delta (F.D.) o empresário por Lima Oscar Uniform (L.O.U.) e o Senador Hotel Lima (H.L.).

\section{DADOS E SUA ANÁLISE}

Visando melhor compreensão do processo é oportuno contar de forma sucinta o motivo pelo qual foi criado o corpo de bombeiros voluntários dos municípios A-B-C. No mês de dezembro do ano de 2000, ao final de uma tarde apareceu um motorista de ambulância pedindo ajuda, pois, havia um acidente grave na BR 470 com várias vítimas que precisavam de auxílio. Na época, J.J.M. secretário municipal da saúde deslocou-se até o local onde estavam atuando o Comandante $(\mathrm{Cmt})$ dos Bombeiros Voluntários do município I. O senhor E.V. e sua equipe, após o episódio passaram a discutir sobre as possibilidades de montar um Corpo de Bombeiros Voluntários nos municípios A-B-C.

Com o auxílio do empresário L.O.U., a ideia do Corpo de Bombeiros Voluntários (CBV) ganhou adesão.

Em reunião com prefeitos e vereadores dos municípios envolvidos e a participação do então Senador H.L., 
Sérgio Luiz Bagattoli; Giane Carla Kopper Müller

foi discutida a necessidade e viabilidade do projeto e sua aprovação. A partir disso, em janeiro de 2001, houve a divulgação e o primeiro curso de formação no município A, onde 35 alunos foram treinados pelo CBV do município l e 30 deles se formaram em novembro de 2001.

As atividades operacionais tiveram início no dia $1^{\circ}$ de dezembro 2001 . O grupo buscava reconhecimento social e político para estruturar a entidade com equipamentos. Sob as premissas de valor, disciplina e abnegação. A estrutura política governamental da época permitiu um rápido crescimento estrutural através de convênios Federais, Estaduais e Municipais, propiciando aos munícipes, tranquilidade, no tocante emergencial, que até então estavam desprovidos.

O município A possuía uma ambulância, mas ela não estava em uso devido às multas de trânsito. Foi sanado o problema e o veículo passou a ser utilizado pelo CBV dos municípios A-B-C para Atendimento Pré-Hospitalar (APH). O Corpo de Bombeiros voluntários dos municípios A-B-C passou por diversas dificuldades e, em certo momento, esteve muito próximo de encerrar suas atividades, devido à falta de verbas para manter o mínimo necessário.

As dificuldades foram vencidas com a ajuda da comunidade, atualmente contam com quinhentos (500) bombeiros voluntários formados para o auxílio, dos quais cento e vinte (120) homens estão na ativa cumprindo com os serviços semanais, e quatro (4) bombeiros são contratados para as funções administrativas e operacionais. Conta ainda com nove (9) veículos nas áreas de socorro, resgate e combate a incêndios.

Desde 2003 são desenvolvidos trabalhos com as crianças da região, formando os Bombeiros Voluntários Mirins, classe 1, com idade entre 7 e 12 anos, Mirins classe 2, com idade entre 13 e 14 anos e Bombeiros Voluntários Aspirantes de 15 a 17 anos.

\title{
4.1 A Formação dos Bombeiros Voluntários
}

O Núcleo de Formação Continuada (NCC) dos Bombeiros é composto pelo Subcomandante dos bombeiros voluntários dos municípios A-B-C e por seis instrutores, dentre eles, este pesquisador, os quais realizaram a seleção dos candidatos inscritos e aprovados para compor a turma 2014, no curso para Bombeiros Voluntários 2014.

Os critérios para a seleção da turma 2014 foram:

- Idade igual ou superior a 18 anos;

- Ensino médio completo;

- Condições físicas e psicológicas adequadas às necessidades do CBV;

- Atestado médico para as atividades de bombeiros;

- Folha de antecedentes criminais;

- Exame físico;

- Disponibilidade para atuar, pelo menos, um turno de trabalho por semana no CBV, após a formatura, cujos turnos são: $1^{\mathrm{a}}-07 \mathrm{~h} 01$ às $14 \mathrm{~h}-2^{\mathrm{a}}-14 \mathrm{~h} 01$ às $20 \mathrm{~h}-3^{\mathrm{a}}-20 \mathrm{~h}$ às $07 \mathrm{~h}$.

Após as entrevistas, avaliação escrita e oral individual com os 46 candidatos, foram selecionados trinta (30) alunos para realizar o curso de Formação dos Bombeiros Voluntários dos Municípios A-B-C de 2014. No processo seletivo, cada aluno fez um relato explicando o motivo pelo qual estava participando do processo de seleção para CBV. Chamou-nos a atenção o relato dos candidatos M.P. e S.M.P., quando analisadas suas respostas.

Por que participar do Corpo de Bombeiro Voluntário?

M.P., - 24 anos, agricultor, ensino médio, respondeu:

\begin{abstract}
Em agosto de 2010 quando eu quebrei a perna trabalhando na roça, logo depois meu irmão ligou para o Bombeiro, vieram me atenderam e fui conduzido até o hospital do município T. Fiquei cinco meses sem trabalhar, e nesse tempo muitas pessoas vieram me visitar inclusive um Bombeiro. Deste momento em diante comecei a gostar dos serviços dos Bombeiros, porque atendem muitas pessoas independentemente da cor, raça ou religião. $E$ foi através do Bombeiro que me visitou que se chama C.B. que fiquei sabendo do curso.
\end{abstract}

S.M.P. - 26 anos, ensino médio, agricultor, respondeu:

Em agosto de 2010 o M.P. quebrou a perna trabalhando na roça, a tarde liguei para os Bombeiros, vieram e o atenderam muito bem e o conduziram para o hospital. Os Bombeiros atendem muitas pessoas independente de ser rico ou pobre, branco ou negro. São muito competentes no atendimento e transmitem muita confiança para a pessoa que está sendo atendida. Isso que ficou em ser Bombeiro. Através do Bombeiro C.B. fiquei sabendo que os Bombeiros forneciam esse Curso de Formação.

Porque o Bombeiro Voluntário escolheria você? 
M.P. respondeu: "porque eu tenho pouco conhecimento em geral".

S.M.P. respondeu: "honestidade, tímido, dificuldade em todas as coisas, no fato de eu ser do interior, acredito que escolheria para ver se eu iria concluir o curso".

Analisando o caso, o que realmente chamou a atenção foi que, eram muito parecidas as respostas dos irmãos " $\mathrm{P}$ ", sendo que não estavam juntos no momento da entrevista, comprovando que realmente algo de muito especial estava por vir.

Em reunião com o NCC, após a apresentação dos prós e contras à entrada de cada aluno no curso, o subcomandante afirmou:

Temos aqui uma situação muito delicada a tratar sobre os irmãos "P". Não devemos aprová- los para o curso de formação deste ano e estaremos fazendo a coisa certa. Eles, por serem tão simples em sua essência serão motivo de chacota entre os demais.

Porém, o instrutor E.W.M. contra argumentou afirmando:

Não deveríamos ao menos dar uma oportunidade a eles? Considerando que houve uma conversa com o Comandante J.J.M., o qual comunicou que dias antes dois jovens, filhos de agricultores, extremamente educados e simples haviam Ihe procurado, perguntando o que teriam que fazer para se inscreverem no curso de Bombeiro.

O subcomandante indagou:"não vejo como eles poderiam ajudar a nossa instituição"

No que E.W.M. completou: "não sei se vão acrescentar algo, mas talvez para eles seja uma oportunidade única e se não conseguirem acompanhar o curso vão desistir ou serão excluídos!"

Palavras do comandante J.J.M.:

\begin{abstract}
Em nossa instituição, anualmente lançamos um curso de formação de Bombeiros Voluntários com duração de $350 \mathrm{~h} / a u l a$, ofertado gratuitamente para os interessados, sendo que para o ingresso, o candidato deve ter no mínimo 18 anos, ensino médio, comprovação de não estar respondendo processos criminais, prova de aptidão física além de boa dicção. Após as avaliações, a coordenação do NCC escolhe 30 alunos para iniciarem o curso.

Na seletiva de 2014, dentre os vários inscritos, 02 alunos que chamaram a atenção das lideranças, por sua apresentação individual, dois irmãos, agricultores que apresentavam grande dificuldade em se expressar, pessoas humildes, com forte sotaque italiano e bastante dificuldade por conta de sua "vergonha" em se relacionar com os demais. Após a avaliação, aconteceria a exclusão de ambos do curso por não apresentarem o mínimo necessário.

A notícia de que eles seriam excluídos gerou certa tristeza, o que me fez conversar com a coordenação do NCC para que fosse dada uma "chance" para ambos, não pelo que eles poderiam contribuir com nossa entidade e sim pelo que nossa entidade poderia contribuir com a vida e formação deles, afinal o convívio com pessoas diferentes, bem como os afazeres do curso poderiam mudar significativamente a postura deles. (J.J.M. Comandante dos Bombeiros Voluntários municípios A-B-C-Santa Catarina 2014).
\end{abstract}

O curso de Formação de Bombeiros Voluntários dos municípios A-B-C do ano de 2014, excepcionalmente iniciou com 32 participantes, os 30 que já haviam sido escolhidos e mais os irmãos "P", S.M.P. e M.P.

No primeiro dia de aula do curso de formação (este pesquisador foi o instrutor) o conteúdo ministrado foi sobre disciplina e trabalho em equipe. Este primeiro encontro tinha como foco a apresentação dos alunos. Cada aluno deveria responder as seguintes indagações: Nome; Idade; Naturalidade; Empresa e setor que trabalha; Função; Uma coisa que gosta; Uma coisa que não gosta; Um filme; A pessoa mais importante pra você; Um lugar; Um sonho; Um líder; Uma palavra que represente você.

No momento de responder as perguntas para dar início as apresentações, os irmãos " $\mathrm{P}$ " apresentaram dificuldade, no que concerne a descrever um filme que se identificassem, sendo orientados que poderia ser qualquer filme, como aventura, romance. Cuja resposta deles foi de que não assistiam filmes. Sobre a descrição de um sonho, responderam, não temos muito tempo para sonhar...

No primeiro mês de curso, ainda no primeiro módulo, alguns alunos desistiram. Enquanto que os irmãos " $\mathrm{P}$ ", que muitos acreditavam não passarem do primeiro mês de aulas, continuavam firmes e determinados.

O curso de formação de bombeiros voluntários é dividido em cinco módulos e o acampamento, conforme descrição:

Módulo 1 - Rádio comunicação e central de atendimentos. Nesta etapa é abordado o contexto da estruturação da corporação, as triagens do atendimento e seus meios de comunicação, tanto no telefone como no rádio comunicador.

Módulo 2 - Combate ao incêndio, o aluno aprende sobre a sua segurança, a de sua equipe e a de terceiros que se encontram próximo aos incêndios, aprende como o fogo se comporta, se propaga e os meios para extingui-lo.

Módulo 3 - Atendimento pré-hospitalar, a maior parte de nossos atendimentos é de ocorrência pré-hos- 
Sérgio Luiz Bagattoli; Giane Carla Kopper Müller

pitalar. Nesta etapa o aluno aprende a lidar com as diversas situações, tais como: traumas, emergências médicas e obstétricas.

Módulo 4 - Atividades específicas, conhecimentos das atividades colocadas como especiais, formação básica. É importante lembrar que para atuar nessas áreas, após o curso de formação, existem especializações em cada área, resgate veicular, resgate em ambientes naturais (mata, cachoeira, caverna etc.), resgate em altura, resgate aquático (no nosso caso principalmente em águas rápidas), acidentes com produtos perigosos e animais peçonhentos.

Módulo 5 - Estágio supervisionado. Esta será a etapa de conclusão do curso. No ano subsequente à formação, o aluno faz um estágio supervisionado, o qual será avaliado sua participação, conhecimento versus aplicação, comportamento condizente com a função.

Acampamento - As atividades do acampamento são direcionadas para o trabalho em equipe e ajuda mútua. Para que possam conhecer, entender e superar seus limites.

Assim que o aluno concluir os módulos, terá que participar de no mínimo 80 horas de estágio em cada módulo, no qual deverá estar devidamente acompanhado por um bombeiro experiente. Concluído os cinco módulos, conforme requisitos de aproveitamento, será considerado apto para iniciar o estágio supervisionado.

\subsection{Feedback dos Instrutores}

Os feedbacks acontecem em diversos momentos, individualmente ou em grupo, conforme a situação e a necessidade, para situá-los sobre a formação enquanto bombeiros voluntários dos munícipios A-B-C.

O primeiro feedback aconteceu no primeiro dia de aula, depois da apresentação dos irmãos "P", observamos que ambos ficaram ainda mais introvertidos, pois, devido a timidez excessiva deles, tinha-se a impressão de que tinham "medo" de falar.

Ambos foram chamados para uma conversa ao final da aula, quando lhes foi dito no feedback:

Ninguém é melhor do que ninguém, as pessoas apenas se diferenciam pelo conhecimento e se depender deste instrutor (que lhes fala) e dos demais instrutores, vocês terão, ao final deste curso, o conhecimento para serem pessoas que se diferenciam entre as demais.

Foi quando brotou um imenso sorriso no rosto dos irmãos S.M.P. e M.P. Isto também revigorou a equipe de instrutores.

Módulo 1: ao final deste módulo, os irmãos S.M.P. e M.P. não conseguiram a nota mínima necessária para a conclusão da primeira etapa. Após o feedback com todos os alunos, foi realizado feedback com os irmãos " $\mathrm{P}$ ". Ao informá-los que não haviam atingido a nota mínima, o S.M.P. olhou-me com lágrimas nos olhos e disse:"não me tire do curso! ". O outro irmão, M.P nem conseguia falar. Foi quando o instrutor reforçou, "não estamos aqui para tirá-los do curso, mas sim para torná-los bombeiros. A força de vontade de vocês supera qualquer prova teórica. Vocês precisam refazer a prova sim, mas isso não significa que estão fora do curso".

Eles não sabiam se choravam ou riam. Foram esclarecidas algumas dúvidas e no encontro seguinte, realizaram a nova avaliação, e conseguiram atingir a média. Na verdade, a única recomendação é que no momento em que iriam atender ao telefone, deveriam prestar atenção para não falarem o idioma italiano que utilizam no dia a dia com seus familiares.

Foi realizado o acampamento e na última atividade, antes de retornarmos para a base foram formadas duas equipes, cujos irmãos " $\mathrm{P}$ ", foram divididos, ficando um em cada equipe. A atividade consistia que cada integrante das equipes, retirava um bilhete de dentro de um saco plástico, que apresentava uma tarefa a ser cumprida, conforme as orientações. Novamente o incrível aconteceu.

Os irmãos S.M.P. e M.P. pegaram o bilhete que dizia: elimine alguém da sua equipe.

A simplicidade deles exigiu que superassem este desafio, foi uma das piores situações, ter que escolher alguém para eliminar. M.P. por sua vez olhou para a sua equipe e ficou sem saber o que fazer, até que alguém da equipe sinalizou "pode me tirar, pode me tirar!". Aquilo foi um alívio para M.P., pois, tinha uma opção.

Já S.M.P. foi além, olhou para a sua equipe, para os instrutores e fez a seguinte pergunta: sou parte da equipe? Os instrutores responderam, obviamente que sim!

S.M.P. prosseguiu, então estou me eliminando.

Assim, os instrutores concluíram que este feedback não foi só para eles, foi para todos que estavam naquele acampamento.

Ao final do módulo 2, era possível notar a evolução dos irmãos "P", eles apresentavam maior entrosamento no contato com as pessoas que estavam na corporação, cumprimentavam a todos na chegada e na saída. Ambos continuavam empolgados como no início do curso. Algo perceptível no dia a dia e principalmente no feedback realizado com o grupo. Vale a pena mencionar que os irmãos " $\mathrm{P}$ ", em especial, estavam sedentos de informação, o que nos remete a conclusão de que, neste caso, o feedback é mais um momento de aprendizado. 
Ao final do módulo 3, grande parte dos alunos tiveram que refazer a avaliação, e para não deixar dúvidas sobre a evolução, o aluno S.M.P obteve a maior nota da turma, desfazendo o tabu "criado" no início do curso.

Ao final do modulo 4, dos 32 alunos que iniciaram o curso, restavam 16, entre os quais os alunos S.M.P. e M.P., os irmãos "P", com 100\% de presença e com o mesmo empenho do primeiro dia de aula.

No dia 30 de novembro de 2014 foi realizada a formatura do curso de bombeiros voluntários e tivemos a oportunidade de conhecer os pais dos irmãos "P", e a eles fizemos a seguinte pergunta: Notaram alguma diferença nos seus filhos após terem iniciado o curso de bombeiro?

O pai respondeu:

No início achei, o que eles vão fazer lá? Não vão receber nada para fazer isso. Mas hoje vejo a diferença que está fazendo na vida de meus filhos, no próprio serviço da roça, já não preciso mais falar muitas coisas como antes, eles percebem o que tem que fazer, e fazem.

A mãe respondeu: "como estou feliz de estar aqui hoje vendo meus filhos (bombeiros). Eles mudaram muito depois de fazer esse curso. Muito obrigada por ajudarem meus filhos, mas tenho uma reclamação, eles não param mais em casa" risos e olhos brilhantes.

Módulo 5 - este módulo iniciou-se no dia $1^{\circ}$ de dezembro de 2014 , cuja data coincidiu com os 13 anos de fundação dos bombeiros voluntários dos municípios A-B-C. Com o término do módulo 5 previsto para o dia $1^{\circ}$ de dezembro de 2015 não é possível adiantar o resultado desta fase.

Qual seu feedback sobre a desenvoltura dos irmãos "P" no curso?

Feedback comandante J.J.M.:

Praticamente 9 meses depois do início do curso, sinto-me alegre e orgulhoso com nossa atitude, pois eles (irmãos "P") têm se destacado nas atividades, tem evoluído muito na relação interpessoal, além de que a ingenuidade de ambos tem conquistado todos que compõe o grupo. Vejo que nós temos aprendido muito com eles e eles conosco. Todos têm ganhado com a experiência, o que fortaleceu a premissa que o homem deve lapidar a si mesmo para realmente saber seu potencial e também considerar que a vontade sincera em prestar serviços voluntários nunca deve ser desprezada. Obviamente um bombeiro mal capacitado é um risco para a sociedade e para ele mesmo, porém, no caso destes dois alunos temos atingido os objetivos na capacitação. (J. J. M. Comandante dos Bombeiros Voluntários 2014 municípios A-B-C - Santa Catarina).

Feedback do subcomandante E.S.:

A minha maior alegria ao final desta trajetória é que eu estava errado em relação aos irmãos "P". Reforçando que minha maior preocupação era exatamente com eles, para não expô-los, mas o que aconteceu foi realmente o contrário, eles nos ensinaram muito. (E.S. subcomandante bombeiros voluntários dos municípios A-B-C 2014).

De feedback do curso e dos desempenhos dos colegas.

Feedback aluno e colega de curso F.D.:

Em 25 de fevereiro, 22h48min, recebi um e-mail do NCC do corpo de Bombeiros Voluntários dos municípios A-B-C, em negrito se destacava a frase: "você foi selecionado (a) para participar do curso de formação de bombeiros voluntários da turma de 2014". Uma grande oportunidade surgia e um sonho de infância começava a se realizar, fazer parte do mundo dos bombeiros. Que demais! Desde o primeiro dia de aula tive muitas dúvidas e muitos medos, que foram superados pelos ensinamentos e segurança passados pelos instrutores que sempre complementavam tudo que nos ensinavam com o incrível espírito de equipe. Em nosso pensamento ficou uma ideia para o futuro, seremos uma equipe, não um grupo. O relacionamento da turma nessa fase inicial ainda era de individualismo, éramos um grupo. Desde o início dois colegas, chamavam a atenção entre os alunos, talvez pela timidez excessiva, talvez pelo biotipo, um tanto franzino perto dos demais. Tive alguns pensamentos, que vejo hoje que foram arrogantes, pois achei que eles não iriam concluir o curso, "vão pedir pra sair", ou até mesmo que seriam excluídos do curso. Que grande "babaca" me sinto por ter pensado isso.

Esses dois colegas são conhecidos como "os irmãos $\mathrm{P}^{\prime}$, pois são irmãos e esse é o sobrenome deles. Esses irmãos surpreenderam toda a corporação, como vou explicar mais à frente. Lembro-me do tão esperado acampamento, evento que era muito temido por todos os alunos, 
Sérgio Luiz Bagattoli; Giane Carla Kopper Müller

pois seríamos testados, a maior dúvida era se, teríamos capacidade de passar.

Nós passamos! O acampamento nos ensinou a vencer medos, a importância de ser uma equipe, de trabalhar unidos, independente do biotipo, idade ou sexo.

Nós conseguimos! Durante a noite no acampamento precisávamos manter a fogueira acesa, fiquei no primeiro turno para manter o fogo, falei para um dos irmãos $\mathrm{P}$ que estava comigo: "precisamos de mais lenha!", em alguns instantes ele retornou, do meio da escuridão carregando um tronco nas costas, foi durante todo evento muito atento e prestativo, trabaIhando muito pela equipe.

Daquele dia em diante passei a prestar mais atenção nos irmãos $\mathrm{P}$, em como são atentos e se ajudam o tempo inteiro.

Com o decorrer do curso, a timidez já não era mais tão acentuada, e é impressionante a evolução de ambos. Um dos irmãos, o S.M.P. se destaca mais nas provas escritas. A vontade de aprender e a preocupação de estar preparado para fazer um bom atendimento é uma constante nesses homens. Posso dizer que quem tem a oportunidade de ter a companhia deles, passa a ter uma aula de humildade, respeito, amizade e superação.

Existe um ditado que diz para não julgarmos o livro pela capa, o que se faz muito verdadeiro, nesse caso. Durante o curso de formação fiz grandes amigos, aprendi a olhar a vida por outra perspectiva, tenho orgulho de dizer que sou amigo dos irmãos "P", e eles em especial me fizeram enxergar além, enxergar também com o coração. (F.D. aluno do curso de formação 2014, texto "Coração de Bombeiro").

\subsection{Análise dos Resultados}

Os resultados podem ser avaliados através dos relatos das pessoas que acompanharam a evolução dos alunos, em especial dos irmãos "P". Um companheiro de turma dos irmãos "P", afirma:

A vontade de aprender e a preocupação de estar preparado para fazer um bom atendimento é uma constante nesses homens. Posso dizer que quem tem a oportunidade de ter a companhia deles, acaba tendo uma aula de humildade, respeito, amizade e superação". (F.D. aluno do curso de formação 2014, parte do texto "Coração de Bombeiro").

Já o instrutor comenta que:

No acampamento eles nos surpreenderam novamente destacando-se nas atividades, demonstrando habilidades e conhecimentos em práticas nas quais os demais alunos tinham dificuldades. Após 09 meses de curso, dos 32 selecionados, 12 desistiram e 04 foram desligados pelo número de faltas, mas os irmãos " $\mathrm{P}$ " apresentam $100 \%$ de frequência e continuam evoluindo, sem perder sua simplicidade e educação. Hoje só tenho a agradecer aos irmãos M.P. e S.M.P., pois aprendi muito com eles". (E.W.M. instrutor do curso de formação de bombeiros voluntários 2014 dos municípios A-B-C).

O comandante menciona:

Vejo que nós temos aprendido muito com eles e eles conosco. Todos ganhamos com a experiência, o que fortaleceu a premissa que homem deve lapidar a si mesmo para realmente saber seu potencial, bem como nenhuma vontade sincera em prestar serviços voluntários deve ser desprezada". (J.J.M. Comandante dos Bombeiros Voluntários 2014 municípios A-B-C - Santa Catarina).

Ao final deste ciclo vemos que uma pedra bruta está sendo lapidada para se tornar um diamante. Sempre acreditando no desenvolvimento das pessoas pelo treinamento acabamos nos surpreendendo com o resultado adquirido neste curso. Como instrutor deste curso de formação também evoluímos e crescemos devido à presença e participação dos irmãos "P".

Por isso, falamos desse resultado com imenso prazer e entusiasmo, pois tem emocionando a muitos, especialmente as pessoas que acompanharam esse trabalho e a evolução destes voluntários. Não por ser uma obra-prima, mas por se tratar de pessoas simples, de seres humanos que erram tentando acertar.

\section{CONCLUSÃO}

Todo conhecimento adquirido ao longo do curso de formação de bombeiros voluntários de 2014 gerou grandes possibilidades de salvar vidas. Vidas estas que podem não ser do seu filho, do seu pai, mas que pode ser do pai de alguém e, indiscutivelmente, filho de alguém. Neste caso, o treinamento e o desenvolvimento ajudam, consideravelmente, a salvar vidas, cujo trabalho realizado com o grupo e, em especial, o desenvolvimento dos irmãos "P", foi em torno da qualificação, construindo conhecimentos, habilidades, atitudes e valores, pois, "Obviamente um bombeiro mal capacitado é um risco para a sociedade e para ele mesmo". (J.J.M. Comandante dos Bombeiros Voluntários municípios A-B-C- Santa Catarina 2014), porém, toda pessoa que é 
treinada ou procura por treinamento para se capacitar, tem a oportunidade de se desenvolver e evoluir.

As dificuldades existem para todos, independentemente da classe social, raça, credo religioso. O diferencial são as pessoas, como elas lidam com os problemas, como e o quê as motiva a continuar buscando seus objetivos. O processo de treinamento e desenvolvimento é um processo que não pode parar. É algo contínuo.

Mas, não acaba por aqui a gratificante jornada de trabalhar com os irmãos " $\mathrm{P}$ ", pois, muito alegra a resposta dada por eles quando feita a pergunta: O que você espera do bombeiro voluntário daqui a 10 anos?

M.P. respondeu: "que continue ajudando as pessoas. Espero estar aqui prestando meu serviço voluntário, quero fazer mais cursos nessa área porque é ainda mais gratificante do que eu imaginava".

S.M.P. respondeu: "quero poder contribuir como bombeiro, como puderam contribuir comigo, quero estar trabalhando ainda aqui com o bombeiro voluntário e vejo a necessidade de buscar mais conhecimento para ajudar as pessoas que precisam".

A educação, honestidade, sinceridade, simplicidade e o caráter, são valores raros nos dias atuais, mas está presente na nossa corporação de bombeiros voluntários e foi muito reforçada com a presença dos irmãos "P".

O aprendizado, o desenvolvimento, a missão cumprida, é um conjunto de situações favoráveis: a equipe, o ambiente, o indivíduo, a motivação. Colocamos como um conjunto de situações favoráveis, pois se não for, não terá a sua finalidade de desenvolvimento e conclusão. O curso de formação de bombeiros voluntários de 2014 iniciou-se com um grupo de 32 pessoas com um objetivo, formarem-se bombeiros, 16 pessoas concluíram. Entre eles os irmãos "P".

Na sociedade e no mundo corporativo os resultados que o treinamento e desenvolvimento apresentam são notoriamente positivos, sendo que as organizações têm enormes vantagens competitivas, conseguindo a retenção de seus talentos e melhorando seus resultados a cada ano.

Somos responsáveis pelo nosso desenvolvimento e pela realização dos nossos sonhos. Há dentro de cada um, uma força, uma motivação que nos leva a perseverar e conquistar os nossos desafios. A minha motivação é a minha família.

\title{
TRAINING AND STAFF DEVELOPMENT: ADDING VALUE TO PEOPLE AND ORGANIZATION
}

\begin{abstract}
The article aims to identify the possibilities of inclusion of people through training and development, carrying out the study at the Center of continuous training of the Fire Department of Santa Catarina. It was developed as a participatory research, through non-structured interviews with open questions, in a Itajaí Valley corporation covering three municipalities along the highway BR 470, which has a high traffic accident rate. The selection process for volunteer firefighters had 46 candidates, among them the brothers "P". In the first stage of the selection, the result presented by the brothers was unsatisfactory, but by decision of the Continuing Training Center both received the opportunity to continue, considering not only performance, but their education, simplicity, humbleness and interest. During the training the resourcefulness of the brothers "P" was observed, being notorious the application of knowledge in daily life, autonomy, forward thinking and judgment in decision making. At the end of the course the P brothers were the ones who had $100 \%$ attendance and considering their initial difficulties, they stood out in the program, being approved with merit. Both opted to take work at the corporation on Sundays with fixed schedule. What was observd was a unique experience that has occurred in training for volunteer firefighters and the various aspects of human development, considering the decision of being willing to learn, motivation; influence of the context, knowledge; team spirit and, above all, the value of human dignity in the simplest aspects, such as friendliness and the desire to do good.
\end{abstract}

Keywords: Training. Development. Knowledge. Motivation. Fire Department Volunteers.

\section{REFERÊNCIAS}

ALMEIDA, M. S. de. et al. Gestão do conhecimento para tomada de decisão. São Paulo: Atlas, 2011.

ARAÚJO, Luis César G. De. Gestão de Pessoas. São Paulo: Atlas, 2006.

BARROS, Aidil Jesus da Silveira; LEHFELD, Neide Aparecida de Souza. Fundamentos de Metodologia Cientifica. 2. ed. São Paulo: Pearson Education do Brasil, 2000.

BOOG, Gustavo G.; BOOG, Magdalena T. Manual de Treinamento e Desenvolvimento. São Paulo: Pearson Prentice Hall, 2006. 
Sérgio Luiz Bagattoli; Giane Carla Kopper Müller

CARVALHO, Antônio Vieira de. Treinamento: princípios, métodos e técnicas. São Paulo: Pioneira Thompson Learning, 2001.

CHIAVENATO, Idalberto. Gerenciando pessoas: o passo decisivo para a administração participativa. 3. ed. São Paulo: Makron Books, 1994.

CHIAVENATO, Idalberto. Gestão de Pessoas: o novo papel dos recursos humanos nas organizações: 3. ed. Rio de Janeiro: Elsevier, 2010.

CURRY, A.; MOORE, C. Assessing information culture: an exploratory model. International Journal of Information Management, v. 23, n. 2, p. 91-110, 2003.

DAVENPORT, T. H.; PRUSAK, L. Conhecimento empresarial: como as organizações gerenciam o seu capital intelectual. Rio de Janeiro: Campus, 1998.

DECENZO, David A.; ROBBINS, Stephen P. Administração de Recursos Humanos. 6. ed. Rio de Janeiro: LTC, 2001.

DENZIN, Norman K.; LINCOLN, Yvonna S. O planejamento da pesquisa qualitativa: teorias e abordagens. 2. ed. Porto Alegre: Artmed, 2006.

FERREIRA, Aurélio Buarque de Holanda. O Dicionário da Língua Portuguesa. 3. ed. Rio de Janeiro: Nova Fronteira, 1999.

GIL, Antônio Carlos. Gestão de Pessoas: enfoque nos papéis profissionais: São Paulo: Atlas, 2001.

GIL, Antônio Carlos. Como elaborar projetos de pesquisa. 4. ed. São Paulo: Atlas, 2002.

HANASHIRO, Darcy Mitiko Mori; TEIXEIRA, Maria Luisa Mendes; ZACCARELLI, Laura Menegon. Gestão do Fator Humano. 2. ed. São Paulo: Saraiva, 2008.

LACOMBE, Francisco José Masset. Recursos Humanos. São Paulo: Saraiva, 2005.

MARRAS, Jean Pierre. Administração de Recursos Humanos. 14. ed. São Paulo: Saraiva, 2011.

MAY, Tim. Pesquisa social: questões, métodos e processos. Porto Alegre: Artmed, 2004.

MORGAN, Garet. Imagem da Organização. São Paulo: Atlas, 1996.

NONAKA, I.; TAKEUCHI, H. Criação de conhecimento na empresa: como as empresas japonesas geram a dinâmica da inovação. 2. ed. Rio de Janeiro: Campus, 1997.

SOTO, Eduardo. Comportamento organizacional: o impacto das emoções. São Paulo: Pioneira Thomson Learning, 2002.

VIDICH, A. J.; LYMAN, S. M. Métodos qualitativos: sua história na sociologia e na antropologia. In: DENZIN, Norman K.; LINCOLN, Yvonna S. (Org.). O planejamento da pesquisa qualitativa: teorias e abordagens. 2. ed. Porto Alegre: Artmed, 2006. p. 49-90.

WILLIANS, R. L. Preciso saber se estou indo bem: uma história sobre a importância de dar e receber feedback. Rio de Janeiro: Sextante, 2005. 